\title{
Transient Analysis and Optimization of A Knuckle Joint
}

\author{
Aisha Muhammad ${ }^{\star 1,3}$, Ibrahim Haruna Shanono ${ }^{2,4}$ \\ ${ }^{1}$ Faculty of Manufacturing Engineering, Universiti Malaysia Pahang, Pekan, Malaysia \\ ${ }^{2}$ Faculty of Electrical Engineering, Universiti Malaysia Pahang, Pekan, Malaysia \\ ${ }^{3}$ Department of Mechatronics Engineering, Bayero University, Kano, Nigeria \\ ${ }^{4}$ Department of Electrical Engineering, Bayero University, Kano, Nigeria \\ ayshermuhd@gmail.com¹, snnibrahim01@gmail.com²
}

\begin{abstract}
Knuckle joint is used to provide movement between rods while transferring force along the pin axis. It has a range of applications such as in robotics, reciprocating engine valve, fulcrum, and suspension bridge. Various cases have been reported of failures in a Knuckle joint due to poor design and strenuous loading condition. For a guaranteed safety of the structure, analysis and optimization of a knuckle joint are required. A cheaper and qualitative production of the knuckle joint can be achieved in a short period through optimization. In this paper, Finite Element Method (FEM) using ANSYS workbench was used to carry out topology optimization, and transient analysis of a knuckle joint where its dynamic response is observed and its weight is reduced through optimization under certain design loading conditions. Weight reduction of $20 \%$, $35 \%$, and $50 \%$ using a structural steel material under a static loading of $1000 \mathrm{~N}$. The optimization process successfully identifies the mass that needs to be removed to minimize both weight and cost without compromising its reliability and durability. The structural design was carried out using SolidWorks software and then imported into the ANSYS workbench for analysis. By the results obtained, it is proved that ANSYS software can be employed by production companies to minimize material wastages and maximize profits while at the same time maintaining product quality and reliability.
\end{abstract}

Keywords: ANSYS, FEA, Joint, Knuckle Joint, Transient

\section{Introduction}

Knuckle joint is used providing little movement between rods while transferring force along the pin axis. It is used in joining two rods lying on the same plane with the axis coinciding with each other. It allows little movement between the rods along the pin axis while transmitting force [1]. It is a mechanical device for joining two joint under loads with a flexible amount of movement [2]. Some examples of knuckle joints include roof truss rod joint, roller chain link, etc. Knuckle joint are made from different types of materials such as grey, white cast and ductile iron [3]. A knuckle joint consist of five main parts: a knuckle pin, an eye end, fork end, Collar and a taper pin as shown in Figure 1.

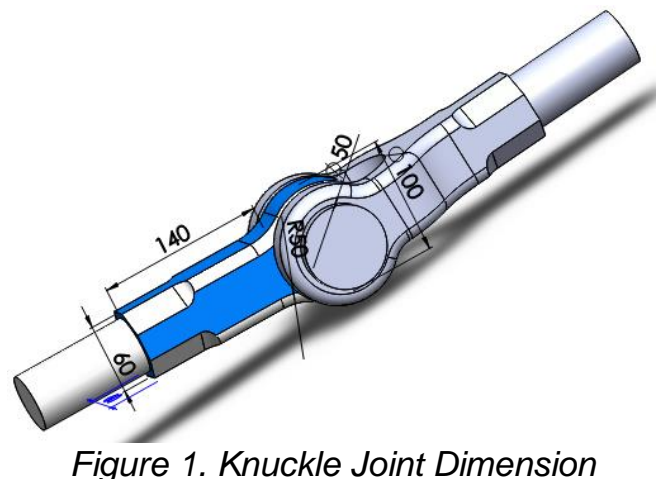

Figure 1. Knuckle Joint Dimension

A knuckle joint has one of its ends tightened with a taper pin and collar; the other end has to have a head [4]. It has a simple design as it can be constructed and reconstructed again when the need requires. A knuckle joint has a range of applications such as in robotics, reciprocating

Muhammad, A., \& Shanono, I. (2019). Transient Analysis and Optimization of A Knuckle Joint. Kinetik: Game Technology, Information System, Computer Network, Computing, Electronics, and Control, 4(2). doi:http://dx.doi.org/10.22219/kinetik.v4i2.767

Receive March 06, 2019; Revise April 08, 2019; Accepted April 09, 2019 
engine valve, fulcrum, suspension bridge, etc. [5]. There have been numerous studies conducted and presented an analysis of a knuckle joint. [6] in their papers used computer Aided Engineering to design a steering knuckle joint and also analyze the model using ANSYS. For the connection of rods together to give a little amount of movement under specific loads, a knuckle joint is used. It can also be utilized for compressive load under certain instructions. However, the connection can be easily removed for corrections or adjustments [4]. A study conducted on the joint of a coupling system shows that failure in a knuckle joint is caused by torsional overload [7]. However, several studies have proved that severe friction which causes the wearing of the material results in delamination wear [8], [9]. [ of. Any of the following modes can result in the failure of a knuckle joint: crushing of pin, shear failure of the pin and the tensile failure of the flat end bar [4]. ANSYS software package is an effective and efficient tool suitable for performing analysis and optimisation of various engineering structures [10]. Before the analysis is done, the meshing of the imported model is done, and design constraints are set [11].

In this paper, Finite Element Method (FEM) using ANSYS work-bench s used to carry out topology optimization, and transient analysis of a knuckle joint in order observe its dynamic response and reduce its weight under the design loading conditions respectively. Weight optimization of the Knuckle joint is carried out with the target weight reduction of $20 \%, 35 \%$, and $50 \%$ using a structural steel material.

\section{Methodology}

Partial differential equations that represent the approximate exact solution of solving a numerical method problem is described as FEM [12]. To solve the engineering problem, FEM is used where-by the structure is subdivided into the smaller element. Using this method, complex structures can be solved making FEM a desirable approach. A numerical method which uses a finite element that involves dividing a system into smaller and simpler parts to find an approximate solution to boundary value problems while minimizing any related error function is known as Finite Element Method [1]. Analysis of any structure begins with the geometry definition which is defined based on the type of simulation analysis that is to be carried out. Since our analysis focuses on stress and deformation, the exact FEA model used is a substructure. Introducing a 3D structure for analysis into the ANSYS software can be achieved by either saving it in an Initial Graphics Exchange Specification (IGES) for-mat and then imported into the ANSYS workbench or can be created in the ANSYS workbench entirely [13], [14], [15]. Depending on the aim of the analysis, some mechanical properties such as density, strength and coefficient of thermal expansion definition is optional [16]. Knowing and declaring the correct value of the material property is very useful for design analysis purpose. Results vary based on the different types of materials having different densities. The Young's modulus of a material is a numerical constant that shows the elasticity and capability of a solid to withstand changes when subjected to tension in a particular direction. The higher Young's modulus, the stiffer the material will require an amount of load to deform. Poisson's ratio and Young's modulus describes the strength and nature of how a material structure deforms based on a particular constraint [17].

Two other essential properties that determine when the material losses it's elastic behaviour and the maximum stress a material can undergo are the yields and tensile strength respectively. After importing the geometry, the definition of an element and material properties is carryout. As outlined earlier, in choosing the material property of the structure, the yield strength is used as a standard [17]. Knuckle joint can be made from different materials and for efficient analysis, correct material properties need to be set. In this study, structural steel is the material used.

\subsection{Transient structural analysis}

The transient analysis is carried out in the Mechanical APDL solver to determine the dynamic response of the knuckle joint given design constraints. To make the model into a single unit to be able to support the set loads during the analysis joint and contact connections are applied. Before the start of the analysis, the body as shown in Figure 2 is made up of four bodies (Collar, knuckle pin, fore eye, and taper pin).

For the contact setting, the Ansys software automatically recognizes the contact area between the bodies. Using the body-body cylindrical joint type an attached joint connection is inserted as shown in Figure 3. To orient and assemble the bodies together, a body-ground fixed joint was added.

KINETIK Vol. 4, No. 2, May 2019: 179-186 


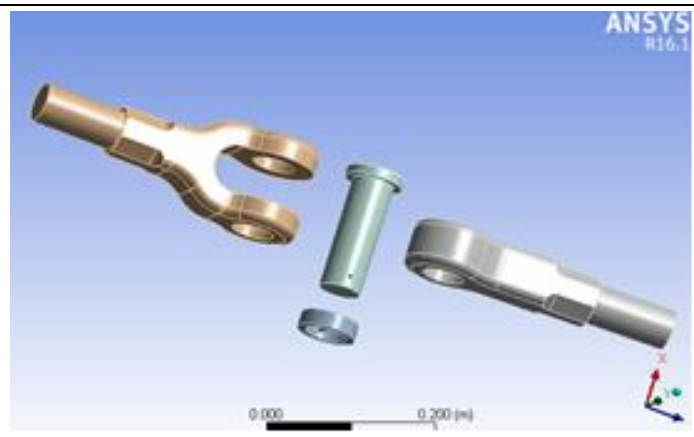

Figure 2. Disjoint Bodies

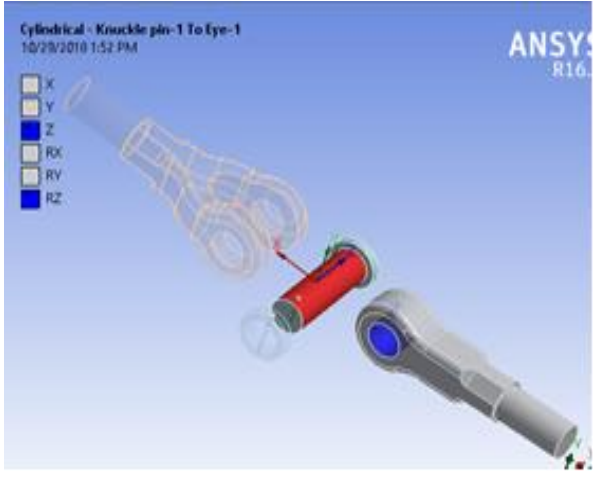

(a)

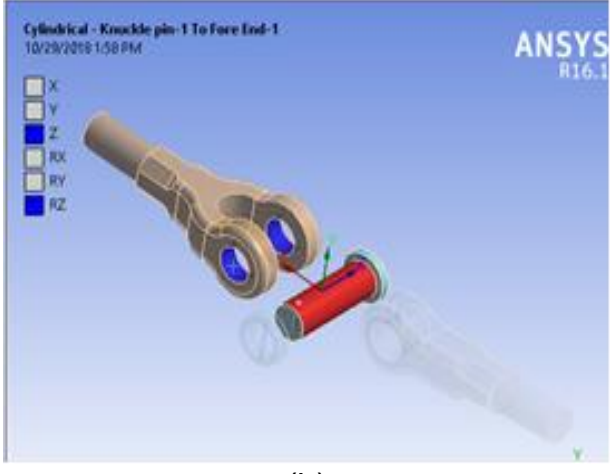

(b)

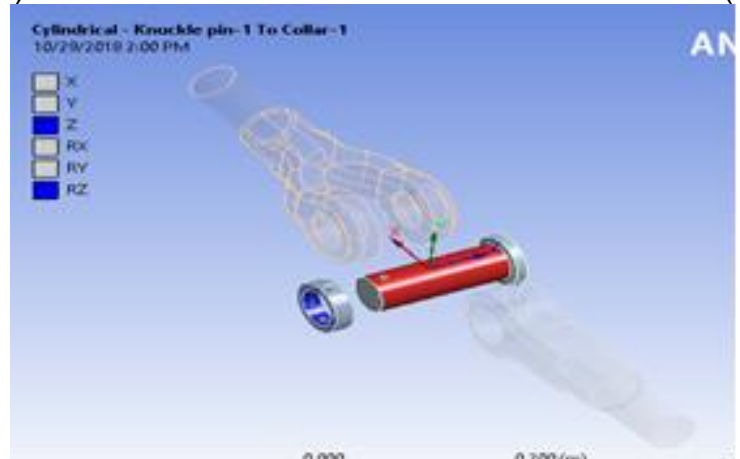

(c)

Figure 3. Cylindrical Body-Body Joints (A) Knuckle Pin-Eye. (B) Knuckle Pin-Fore End (C) Knuckle Pin-Collar

The disjoint knuckle pin and eye need a fixed joint between them. To achieve that, two coordinate systems and a fixed joint are positioned between them. Constraints setting is essential and serves as a primary step required in the analysis [18]. Constraints are set in a way that obeys real-life situations [13]. Figure 4 shows the constraints set in this analysis

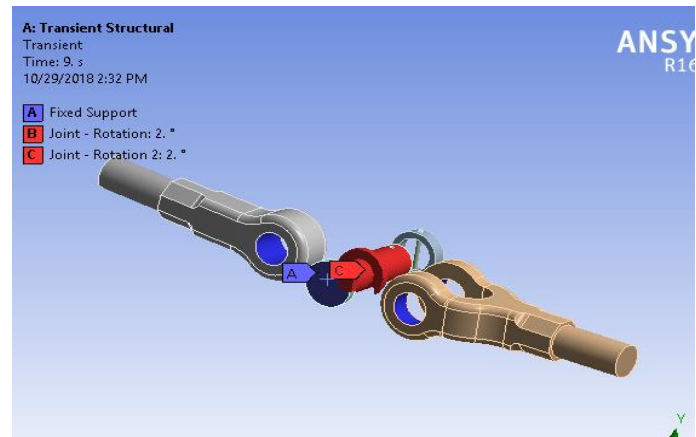

Figure 4. Constraints Setting 


\subsection{Shape Optimization}

Failure of a system will result in the risk of life as well as financial loss. Just like in the human context, when the human body does much work, it becomes stressed, sick and finally, nervous break-down may occur. Also, in an engineering structure, failure may occur when a structure is subjected to a high amount of stress [10]. The amount of pressure in an engineering model that happens when it is exposed to external force or load is termed as stress, which indicates that the applied load is a function of the amount of stress [19]. The main aim of optimization is minimizing the mass and cost with the load range of the connecting rod.

To ascertain the failure of a knuckle joint, the maximum (Von-Mises) stress and deformation are determined. Before carrying out the analysis, constraints need to be carefully applied based on the prevailing conditions [3]. One end of the knuckle pin is fixed while a static force of values $1000 \mathrm{~N}$ is applied on the other end as shown in Figure 5. The weight optimization for the knuckle joint is carried out with the target weight reduction of 20,35 , and $50 \%$ under the said constraints to determine the mass that needs to be removed to minimize cost.

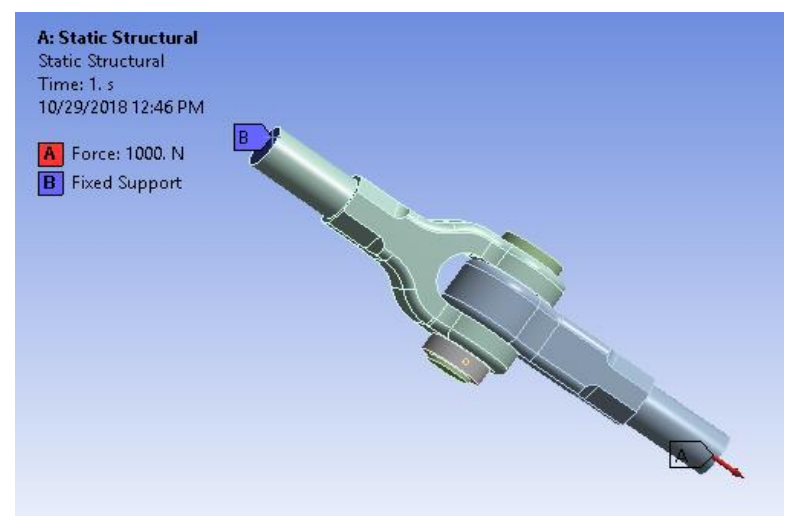

Figure 5. Boundary Conditions

\section{Results and Discussion.}

\subsection{Transient Analysis result}

A designer uses Von-Mises stress analysis to ascertain the failure of his design structure. Failure is inevitable when the strength of the material used is less than the maximum value of the stress. It describes the load carrying ability of a structure to the actual loads [10]. Designers use it in assessing if a design is safe. It indicates that the stress of a point in a structure or model is higher than the material strength [19]. Conforming to the analysis type (transient structural analysis), the solution options are defined. A multiple step analysis type is defined with a step number of 10.

The time-varying deformation, stress and pressure for the transient analysis result are as shown in Figure 6 . The deformation is shown in Figure 6 (a). The maximum deformation stands at $6.1509 \mathrm{e}-005 \mathrm{~m}$ which is indicated by the red color at the tip of the Shaft and the minimum deformation of $0 \mathrm{~m}$ located at the fork. Figure 6 (b) shows the stress distribution level across the knuckle joint. There appeared to have no overstressed visible region.

Table 1 shows the numerical values of maximum deformation and equivalent stress for the knuckle joint. For visual understanding, the tabular parameters are plotted and represented graphically in Figure 7. The plot has a primary and secondary axis representing the equivalent stress and deformation respectively. Both graphs obey the existing theorem, in that the deformation increases are in direct proportional with the stress both attaining maximum values of $1.91 \mathrm{E}-02 \mathrm{~m}$ and $2.70 \mathrm{E}+10$ at 6 seconds.

Table 2 shows the Joint Probe resultant forces in the $X, Y$ and $Z$ plane and the total resultant force. To see the force variation with respect to time, the parameters are represented in the graphical form given in Figure 8. As shown by the graph, the majority of the force is concentrated towards the $\mathrm{X}$-axis with the maximum experienced at 6 seconds. The resultant force in the $z$-axis remains constant at zero throughout the period. While the $y$-axis exhibits Gaussian characteristic attaining its peak at 6 seconds with a force value of $2.04 \mathrm{E}+6 \mathrm{~N}$. Hence, the total resultant force is towards the $\mathrm{x}$-axis with a slightly higher magnitude than that of the $\mathrm{x}$-axis.

KINETIK Vol. 4, No. 2, May 2019: 179-186 


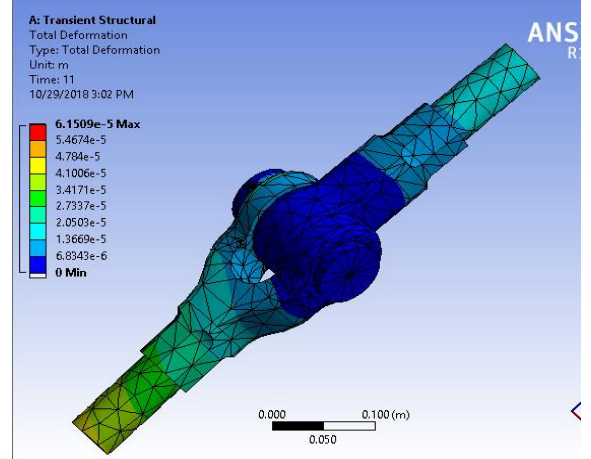

(a)

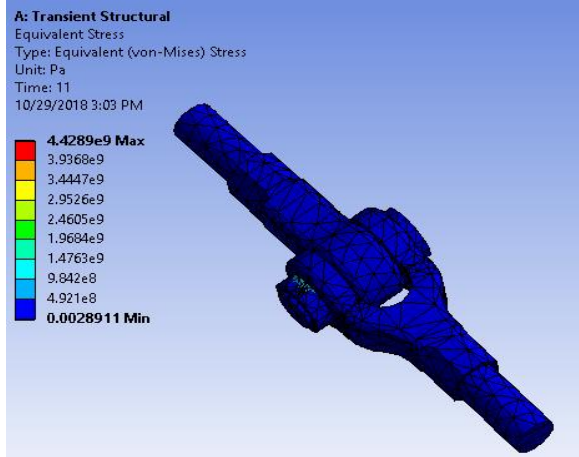

(b)

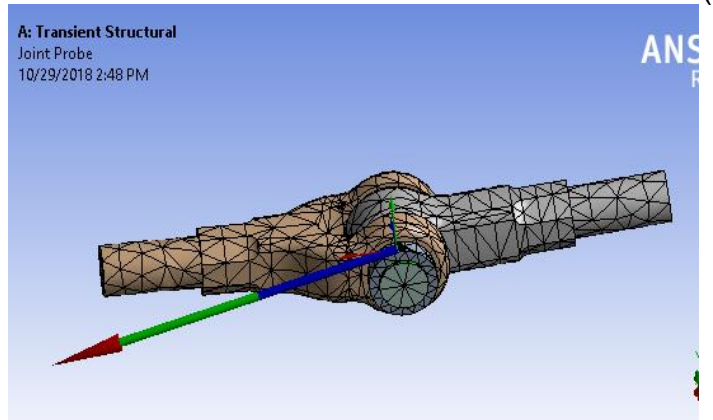

(c)

Figure 6. (A) Total Deformation. (B) Equivalent Von-Misses Stress. (C) Joint Probe

Table 1. Deformation and Stress

\begin{tabular}{ccc}
\hline Time $[\mathrm{s}]$ & $\begin{array}{c}\text { Maximum } \\
\text { Deformation } \\
{[\mathrm{m}]}\end{array}$ & $\begin{array}{c}\text { Maximum } \\
\text { Equivalent } \\
\text { Stress [Pa] }\end{array}$ \\
\hline 1 & $1.23 \mathrm{E}-16$ & $6.40 \mathrm{E}-03$ \\
2 & $3.84 \mathrm{E}-03$ & $5.31 \mathrm{E}+09$ \\
3 & $7.68 \mathrm{E}-03$ & $1.06 \mathrm{E}+10$ \\
4 & $1.15 \mathrm{E}-02$ & $1.59 \mathrm{E}+10$ \\
5 & $1.53 \mathrm{E}-02$ & $2.13 \mathrm{E}+10$ \\
6 & $1.91 \mathrm{E}-02$ & $2.70 \mathrm{E}+10$ \\
7 & $1.53 \mathrm{E}-02$ & $2.16 \mathrm{E}+10$ \\
8 & $1.15 \mathrm{E}-02$ & $1.63 \mathrm{E}+10$ \\
9 & $7.63 \mathrm{E}-03$ & $1.10 \mathrm{E}+10$ \\
10 & $3.80 \mathrm{E}-03$ & $6.52 \mathrm{E}+09$ \\
\hline
\end{tabular}

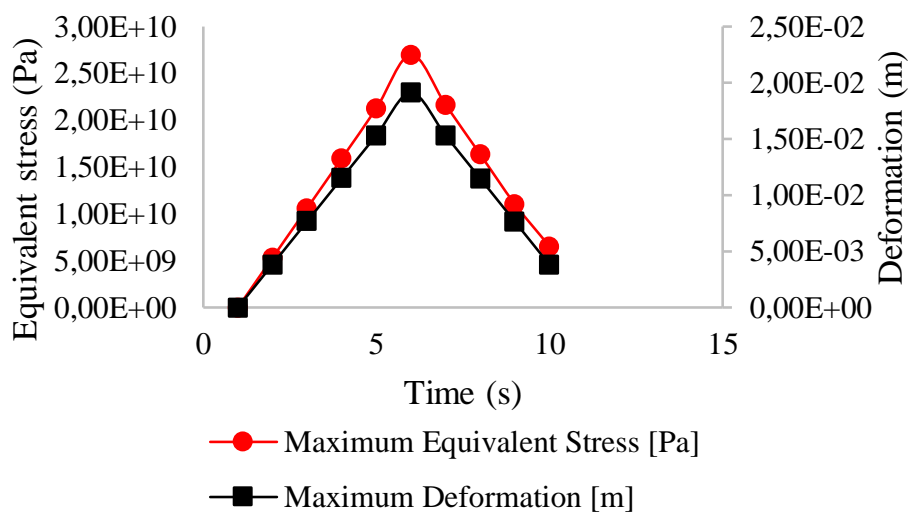

Figure 7. Equivalent and Deformation Curves 


\begin{tabular}{ccccc}
\multicolumn{5}{c}{ Table 2. Joint Probe } \\
\hline \multicolumn{5}{c}{ Joint Probe } \\
Time [s] & $\begin{array}{c}\text { Total Force X } \\
{[N]}\end{array}$ & $\begin{array}{c}\text { Total Force } \\
\mathrm{Y}[\mathrm{N}]\end{array}$ & $\begin{array}{c}\text { Total Force } \\
\text { Z [N] }\end{array}$ & $\begin{array}{c}\text { Total Force } \\
\text { Total }[N]\end{array}$ \\
\hline 1 & $-4.0294 \mathrm{E}-07$ & $-1.0666 \mathrm{E}-06$ & $2.11 \mathrm{E}-22$ & $1.14 \mathrm{E}-06$ \\
2 & -13707 & 86521 & $5.36 \mathrm{E}-14$ & 87600 \\
3 & $1.28 \mathrm{E}+05$ & 63408 & $3.09 \mathrm{E}-15$ & $1.43 \mathrm{E}+05$ \\
4 & $5.17 \mathrm{E}+05$ & -8393 & $-1.10 \mathrm{E}-14$ & $5.17 \mathrm{E}+05$ \\
5 & $1.15 \mathrm{E}+06$ & $-2.41 \mathrm{E}+05$ & $-2.64 \mathrm{E}-14$ & $1.17 \mathrm{E}+06$ \\
6 & $2.04 \mathrm{E}+06$ & $2.04 \mathrm{E}+06$ & $-1.21 \mathrm{E}-13$ & $2.07 \mathrm{E}+06$ \\
7 & $1.39 \mathrm{E}+06$ & $-2.02 \mathrm{E}+05$ & $4.96 \mathrm{E}-14$ & $1.40 \mathrm{E}+06$ \\
8 & $9.53 \mathrm{E}+05$ & $-1.88 \mathrm{E}+05$ & $7.59 \mathrm{E}-15$ & $9.71 \mathrm{E}+05$ \\
9 & $8.53 \mathrm{E}+05$ & $-2.06 \mathrm{E}+05$ & $3.89 \mathrm{E}-15$ & $8.77 \mathrm{E}+05$ \\
10 & $7.76 \mathrm{E}+05$ & $-2.37 \mathrm{E}+05$ & $1.39 \mathrm{E}-14$ & $8.12 \mathrm{E}+05$ \\
\hline
\end{tabular}

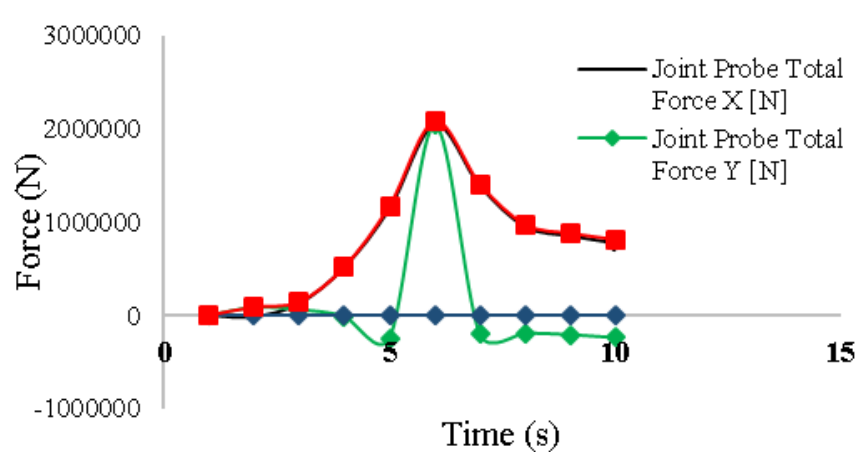

Figure 8. Joint Probe

\subsection{Shape Optimization result}

Shape optimization of the knuckle joint is carried out in order to reduce the weight that is needed in its construction which minimizes the cost by saving the amount of material. Figure 9 shows the result of the weight optimization using a target weight reduction of 20,35 to $50 \%$ respectively under the constraints of a $1000 \mathrm{~N}$ static force.

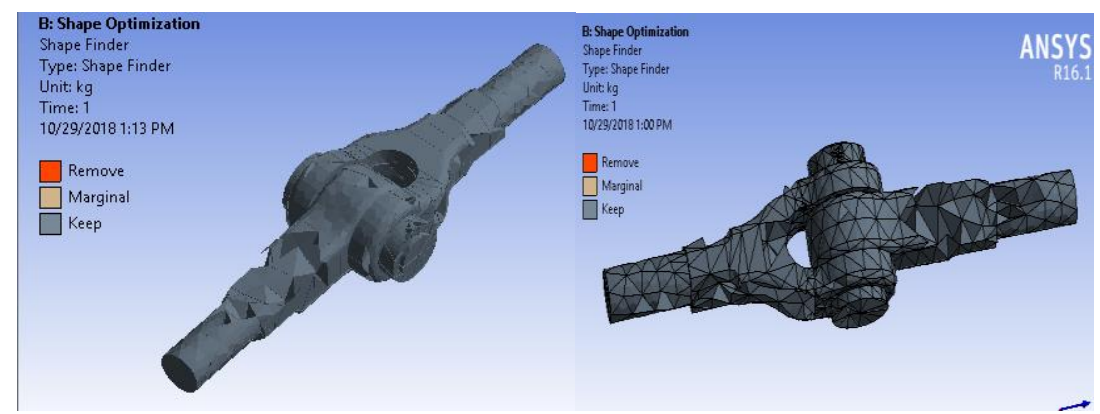

(a)

(b)

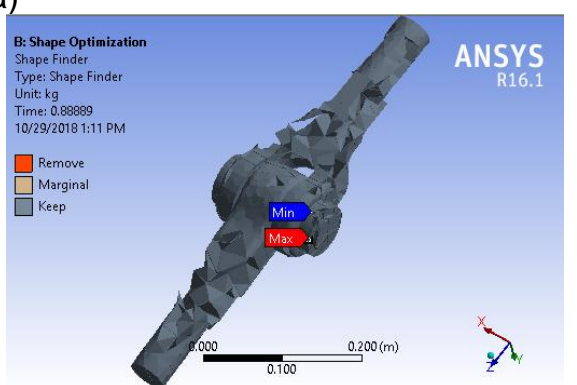

(c)

Figure 9. Shape Optimization (a) 20\%. (b) $35 \%$. (c) $50 \%$

KINETIK Vol. 4, No. 2, May 2019: 179-186 
The optimization result for the various percentages is summarized in a tabular and graphical representation as shown in Table 3 and Figure 10 respectively

Table 3. Weight Optimization

\begin{tabular}{cccc}
\hline Target Reduction & $20.00 \%$ & $35.00 \%$ & $50.00 \%$ \\
Original Mass $(\mathrm{kg})$ & 19.372 & 19.372 & 19.372 \\
Marginal Mass $(\mathrm{kg})$ & $7.70 \mathrm{E}-02$ & $5.97 \mathrm{E}-02$ & 0.16236 \\
Optimized Mass $(\mathrm{kg})$ & 17.214 & 15.639 & 14.037 \\
\hline
\end{tabular}

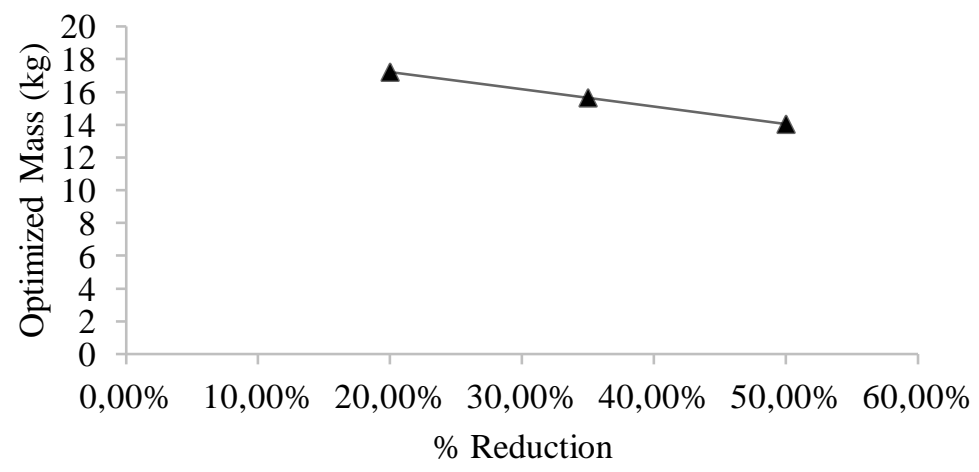

Figure 10. Optimized Mass Comparison

\section{Conclusion}

In this work, Finite Element Method (FEM) using ANSYS workbench was used to carry out topology optimization, and transient analysis of a knuckle joint in order observe its dynamic response and reduce its weight under the design loading conditions respectively. Weight optimization of the Knuckle joint is carried out with a target weight reduction of $20 \%, 35 \%$, and $50 \%$ using a structural steel material under a static loading of $1000 \mathrm{~N}$, which deter-mines the mass that needs to be removed to minimize both weight and cost without compromising its reliability and durability. The knuckle joint structure was designed using SolidWorks software and then imported into the ANSYS workbench for analysis. Based on the results obtained, it can be concluded that ANSYS software can be employed by production companies to minimize material wastages and maximize profits at the same time maintaining product quality and reliability.

From the transient analysis result of the knuckle joint model maximum deformation stands at $6.1509 \mathrm{e}-005 \mathrm{~m}$ which is indicated by the red color at the tip of the Shaft while the stress distribution level across the knuckle joint appeared to have no overstressed visible region.

This paper provides an introduction to FEM for engineering systems with similar models and gives away for future research for structural optimization of the structural design.

\section{References}

[1] A. R. Jha , R.Jaiswal , A. Karki , A. Basnet, S. Jaiswal , P. Jaiswal , and D Rajgadia, "Design and Finite Element Analysis of Knuckle Joint Using CATIA and ANSYS Workbench", (International Journal of Research in Mechanical Engineering, Vol. 4, No. 3, Pp. 01-05, 2016.

[2] Rao, P. Ganesh, and J. B. Bhaskara, "Structural Static Analysis of Knuckle Joint", (International Journal and mag-azine of Engineering, Technology, Management and research, Pp. 656-666, 2016.

[3] M.P. Sharma, D.S. Mevawala, H. Joshi, and D.A. Patel DA, "Static Analysis of Steering Knuckle and Its Shape Optimization", (IOSR Journal of Mechanical and Civil Engineering, Pp. 34-38. 2016

[4] N. Patil, S. M. Sable, and K. Munde K, "Static Structural Analysis of knuckle joint", (International Journal of advanced technology in Engineering and Science, Pp 119-125, 2016.

[5] V. Bhandari, "Design of Machine Elements" (Third Edition), New Delhi, Delhi, India: Tata McGraw-Hill Education Pvt. Ltd, 2012. 
[6] S. Yadav , R.K. Mishra, V. Ansari, and S.B. Lal, "Design and Analysis of Steering Knuckle Component", (Inter-national Journal of Engineering Research \& Technology (IJERT), Vol. 5, No. 4, Pp. 457-463, 2016.

[7] G. Pantazopoulos, A. Sampani, and E. tsagaridis, "Torsional failure of a knuckle joint of a universal steel coupling system during operation- A case study", (Engi-neering Failure Analysis, Vol. 14, No. 1, Pp. 73-84, 2007.

[8] G. Pantazopoulos and S. Antoniou, "Wear related failure of nitrocarburized steels: some microstrucral and morphological observations", (Journal of Failure Analysis Prevention, Vol. 4, No. 6, Pp. 51-57, 2004.

[9] P. Psyllaki, G. Kefalonikas, G. Pantazopoulos, S. Antonious, and J. Sideris, "Microstructure and tribological behaviour of liquid nitrocarburised tools steels", Surface and Coatings Technology, Vol. 162, No. 1, Pp. 67-78. 2002.

[10] M. Aisha and I. H. Shanono, "Strength analysis and structural optimisation of an I-shaped bracket”, (Nigerian Journal of Technological Research, Vol. 13, No 2, Pp. 14-19, 2018.

[11] J.K. Gupta and R.S. khurmi, "A textbook of machine design, New Delhi: Eurasia Publishing House (PVT.) LTD., 2005.

[12] C. Xiaolin and Y. Liu, "Finite Element Modeling and Simulation with ANSYS Workbench, London NewYork: CRC Press, 2014.

[13] W.Guanzhu, Z. Guoqing, Y. Jiancheng, G. Youping, G. Wei, and Z. Hengcai, "Modal analysis of high-speed spindle based on ANSYS, in 2012 7th International Conference on Computer Science \& Education (ICCSE), Mel-bourne, 2012, VIC, Australia.

[14] B. S. Kim, S. H. Lee, M. G. Lee, J. Ni, J. Y. Song, and C. W. Lee, "A comparative study on damage detection in speed-up and the coast-down process of grinding spindle-typed rotorbearing system", (Journal of Materials Processing Technology, Vols. 187-188, Pp. 30-36, 2007.

[15] G.H Jang, S. H. Lee, M.S. Jung, "Free vibration analysis of a spinning flexible disk- spindle system supported by a ball bearing and flexible shaft using the finite element method and substructure synthesis", (Journal of Sound and Vibration, Vol. 251, No. 1, Pp. 59-78, 2002.

[16] E.J. Barbero, 'Finite Element Analysis of Composite Materials Using ANSYS, US: CRC Press, 2013.

[17] A Muhammad and I. H. Shanono," Finite Element Analysis of a Base Stand Using Different Materials", Science, Technology and Arts Research Journal 10-18, 2018.

[18] B. Talikoti, S.N. Kurbet, V.V Kuppast, and M. Arvind M, "Harmonic analysis of a two-cylinder crankshaft using ANSYS", in 2016 International Conference on Inventive Computation Technologies (ICICT), 2016 Coimbatore, India.

[19] A. Muhammad and I.H. Shanono, Structural Analysis of a Knuckle Joint using different materials, in 1st International Civil Engineering Conference (ICEC 2018), 2018, Nigeria. 